\title{
The Role of $\gamma$-Al2O3 Single Crystal Support to Pt Nanoparticles Construction
}

\author{
Zhongfan Zhang*, Long Li*, Lin-lin Wang**, Sergio I. Sanchez***, Qi Wang****, \\ Duane D. Johnson**, Anatoly I. Frenkel****, Ralph G. Nuzzo***, Judith C. Yang* \\ * Department of Mechanical Engineering and Materials Science, University of Pittsburgh, \\ Pittsburgh, PA 15261 \\ ** Department of Materials Science and Engineering, Iowa State University, Ames, Iowa \\ 50011-2300 \\ ***Department of Chemistry, University of Illinois at Urbana-Champaign, Urbana, IL \\ 61801 \\ **** Department of Physics, Yeshiva University, New York, NY 10016
}

Here we report the preparation of a model $\mathrm{Pt} / \gamma-\mathrm{Al}_{2} \mathrm{O}_{3}$ catalyst and its characterization by a cross-sectional high-resolution electron microscopy (XHREM) method. $\mathrm{Pt} / \gamma-\mathrm{Al}_{2} \mathrm{O}_{3}$ is the most important technologically-relevant heterogeneous catalyst in the fuel cell, oil refining and chemical industries. The nanoparticle/support interactions, particularly the role of their interface, play a key role in the 3-dimensional (3D) particle shape, surface morphology and sintering behaviors of catalyst nanoparticles (NPs) which determine the heterogeneous catalysts' chemical properties. Experimental measurements [1] and theoretical simulations [2] were initiated to quantitatively study the interfacial atomic and electronic structure and adhesion energy between the NPs and their support. Previous investigators have used single crystal oxide supports to resolve the nanoparticle/support structure and shape relations that can be directly compared to the theoretical simulations [2]. However, commercial $\gamma-\mathrm{Al}_{2} \mathrm{O}_{3}$ is polycrystalline and irregular in shape; hence, our aim is to create a single crystal $\gamma-\mathrm{Al}_{2} \mathrm{O}_{3}$ thin film in order to build up a model system to solve the structural and electronic relations between the Pt and $\gamma-\mathrm{Al}_{2} \mathrm{O}_{3}$ support, and compare our experimental results with theoretical predictions.

The $\gamma-\mathrm{Al}_{2} \mathrm{O}_{3}(111)$ thin film was prepared via oxidization of $\beta-\mathrm{NiAl}(110)$ at $\mathrm{T}=850^{\circ} \mathrm{C}$ and dry air for 1 hour, while the primary orientation relation (O.R.) was determined to be $\mathrm{NiAl}(011)[110] \| \gamma-\mathrm{Al}_{2} \mathrm{O}_{3}(111)[211]$ and $\mathrm{NiAl}(011)[100] \| \gamma-\mathrm{Al}_{2} \mathrm{O}_{3}(111)[110]$ which is the classical Nishiyama-Wasserman O.R., Figure.1. Pt NPs were deposited onto $\gamma-\mathrm{Al}_{2} \mathrm{O}_{3}(111)$ surface by electron-beam evaporation under ultrahigh vacuum. High-angle annular darkfield (HAADF) imaging and HREM imaging (Figure. 2a and b) shows a significant fraction of the Pt NPs covering the support with intimate contact to the $\gamma-\mathrm{Al}_{2} \mathrm{O}_{3}$ support. The shape of the Pt NPs is a truncated octahedron which correlates with a dewetting shape, Figure 2c. The dominant surface facets are the $\{111\}$ and $\{100\}$ low-index planes which are the favorable facets for catalytic reactions [3]. The O.R. of the Pt NPs was found to be $\mathrm{Pt}(111)[211] \| \gamma-\mathrm{Al}_{2} \mathrm{O}_{3}(111)[211]$ and $\mathrm{Pt}(100)[011] \| \gamma-\mathrm{Al}_{2} \mathrm{O}_{3}(111)[211]$, Figure.2b and c, where the interface planes $\operatorname{Pt}(110) \| \gamma-\mathrm{Al}_{2} \mathrm{O}_{3}(110)$ followed the classical lattice matching epitaxy. Considering that the $\gamma-\mathrm{Al}_{2} \mathrm{O}_{3}$ support has a strong impact on the structural shape and electron density of the catalytic NPs, as an extension of the Wulff construction for 3D facets, Kaishew theorem, was used to analyze the support effects on the Pt particle shape. Electron energy-loss spectrum (EELS) will be applied to study the electronic structure of Pt NPs and clarify the preferred Pt anchoring sites on the $\gamma-\mathrm{Al}_{2} \mathrm{O}_{3}$. 
References

[1] Charles T Campbell, et al. Journal of the American Chemical Society,2002,124, 9212.

[2] P. Nolte, A. Stierle, et al. Science, 321, 1654-8 (2008).

[3] Erik Schmidt, et al. Journal of the American Chemical Society 131, 12358-67 (2009).

[4] Acknowledge to DOE-BES(DE-FG02-3ER15476); we kindly thank N.T. Nuhfer (Carnegie Mellon University), J. Liu and R.R. Cerchiara (Fischione Instruments, Inc.) for their assistance. Equipments at NFCF, University of Pittsburgh, at FS-MRL, University of Illinois at Urbana-Champaign, were used for the TEM sample preparation and imaging.

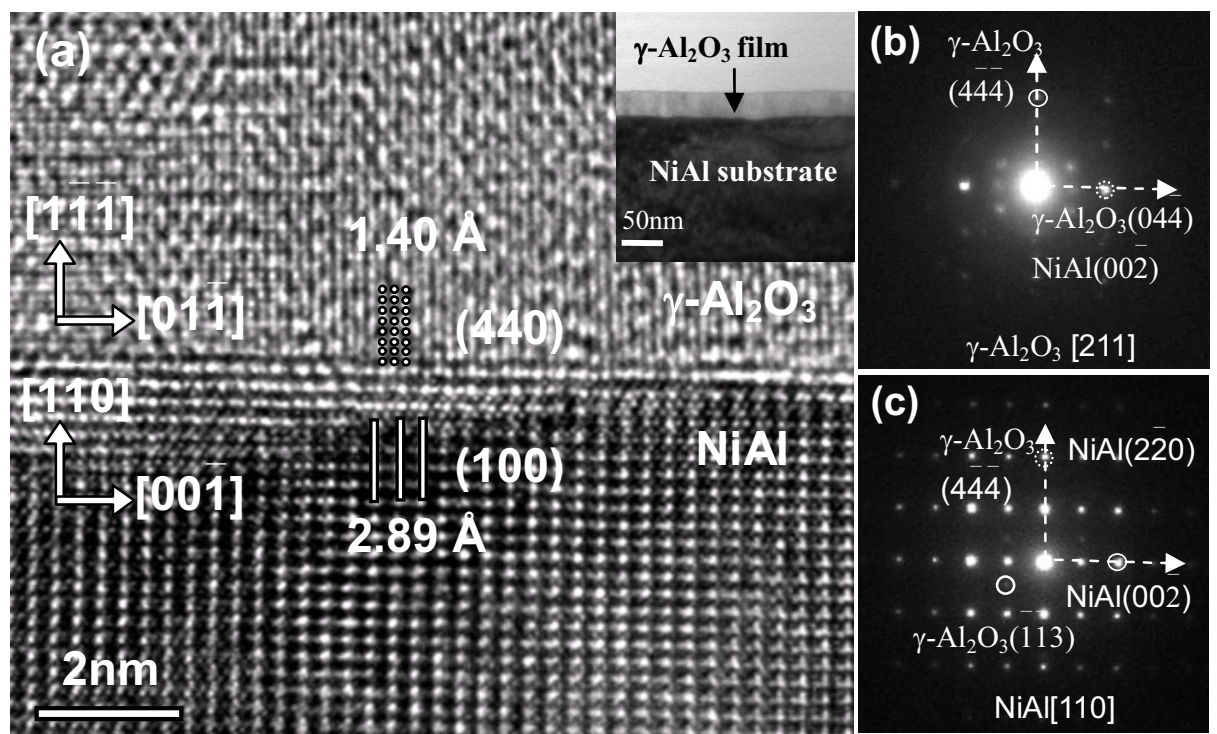

Figure.1 (a) Cross-sectional HREM image of $850{ }^{\circ} \mathrm{C}$ lhour oxidized $\mathrm{NiAl} / \gamma-\mathrm{Al}_{2} \mathrm{O}_{3}$ interface, (b). NB-EDP from upper $\gamma-\mathrm{Al}_{2} \mathrm{O}_{3}$ film, (c). SAD from $\mathrm{NiAl} / \gamma-\mathrm{Al}_{2} \mathrm{O}_{3}$ interface.
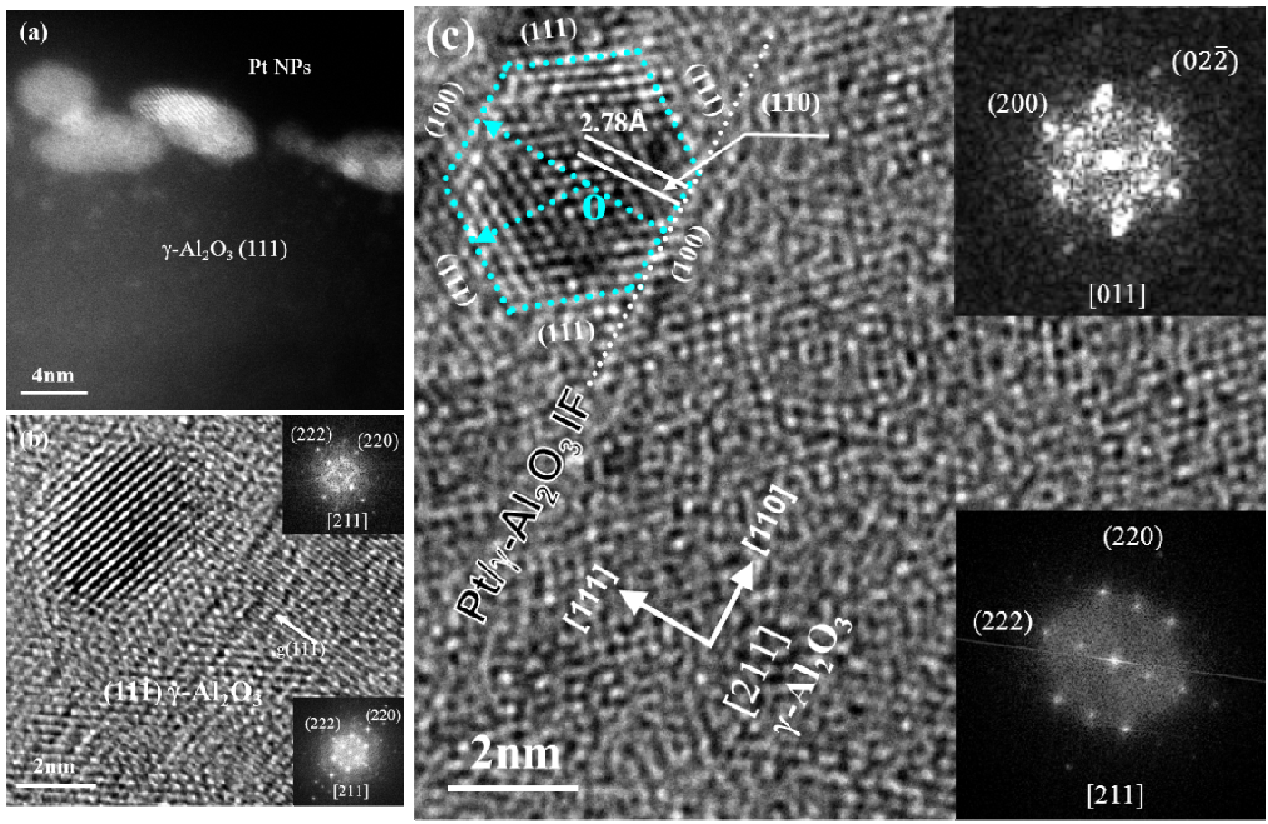

Figure.2. HAADF image (a) and HREM image (b) shows the Pt NPs directly seated on the $\gamma-\mathrm{Al}_{2} \mathrm{O}_{3}(111)$, ES Pt NP Pt (c) with interface planes: $\operatorname{Pt}(220) \| \gamma-\mathrm{Al}_{2} \mathrm{O}_{3}$ (440). 